\title{
Visceral fat and respiratory complications
}

\author{
Luca Busetto and Giueseppe Sergi \\ Department of Medical and Surgical Sciences, University of Padova, Padova, Italy
}

Keywords: obesity, fat distribution, sleep disordered breathing, ventilatory abnormality

Received 13 October 2003; returned for revision 7 April 2004; revised version accepted 20 April 2004

\section{Introduction}

In the last 20 years, fat distribution has been considered a crucial causative factor of the excess morbidity and mortality found in obese patients. Several experimental evidences definitely linked visceral fat accumulation to metabolic disturbances [1-5]. The evaluation of fat distribution by the simple measurement of the waist circumference has been therefore suggested by guidelines to determine cardiovascular risk of overweight in obese patients [6]. At the same time, less attention has been paid to the relationship between visceral fat accumulation and respiratory complications, despite these complications frequently represented an important clinical problem in obese patients.

This review focuses on the role played by visceral fat accumulation on the decrease of pulmonary function and on the prevalence of obstructive sleep apnoea syndrome (OSAS) in obese patients. The effects of weight loss in respiratory complications will be also briefly summarized with a particular emphasis on the role played by visceral fat removal.

\section{Visceral Fat and Pulmonary Volumes}

It is established that obesity reduces respiratory function. Obese patients are typically affected by a restrictive respiratory impairment, with the most characteristic pulmonary function abnormality being a reduction of the expiratory reserve volume (ERV) [7,8]. By categorizing 48 morbidly obese male and female patients according to computed tomography (CT)-determined abdominal fat distribution, Enzi et al. [9] proved that patients with visceral obesity had lower ERV than patients with subcutaneous obesity and same body mass index (BMI) levels. The reduction of ERV was associated with a reduction of the arterial oxygen tension [9]. Measuring pulmonary volumes in 42 male fire fighters with normal weight or mild obesity, Collins et al. [10] confirmed that men with upper body fat distribution [waist-to-hip ratio $(\mathrm{WHR}) \geq 0.950$ ] had forced vital capacity (FVC) lower than men without abdominal obesity.

In population studies, adjusted FVC was negatively associated with the waist circumference values in 621 men from the Pilot Survey of Fitness of Australians [11], 1094 men from the Baltimora Longitudinal Study on Ageing [12] and 865 men from the Fourth Scottish Monitoring Trends and Determinants in Cardiovascular Disease (MONICA) cross-sectional survey [13]. In women, the relationship between fat distribution and pulmonary volumes was less established. In the Baltimora Longitudinal Study on Ageing, larger values of WHR were associated with greater decrease of FVC in men (beta $=1.383, \mathrm{p}=0.005)$ compared to women (beta $=$ $-0.679, p=0.02$ ) [12] (figure 1). In the Fourth Scottish MONICA survey, the effects of increasing waist circumference values on FVC were similar in men (beta $=$ $-0.008, p=0.04$ ) and in women (beta $=-0.007$, $\mathrm{p}=0.01$ ) [13]. Existing data suggested that visceral fat accumulation was strictly related to restrictive respiratory impairment in men. In women, the association was probably weaker and appeared only when highly reliable indexes were used to estimate visceral fat accumulation.

\section{Correspondence:}

Dr Luca Busetto, Clinica Medica I, Policlinico Universitario, Via Giustiniani 2, 35128 Padova, Italy E-mail:

luca.busetto@unipd.it 


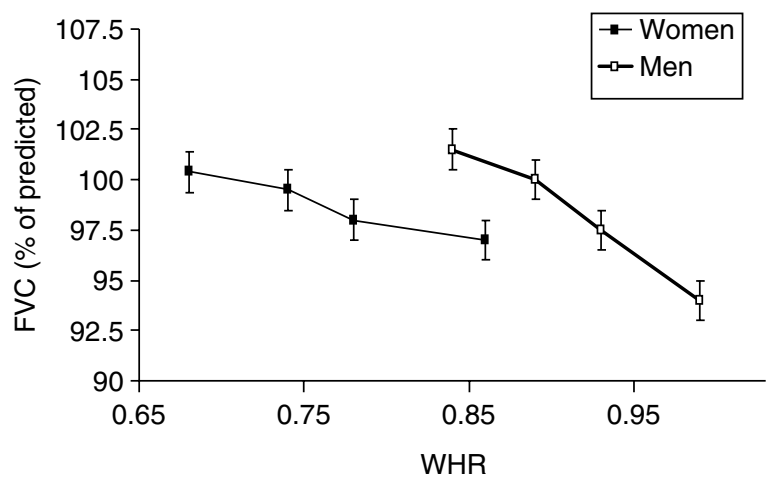

Fig. 1 Variations of forced vital capacity (FVC) with increasing levels of waist-to-hip ratio (WHR) in men and women from the Baltimora Longitudinal Studies of Ageing [12].

The decrease of ERV and FVC associated with abdominal obesity has been attributed to a mechanical effect played by visceral fat accumulation. Fat accumulation in the abdominal cavity increases intra-abdominal pressure [14]. The increase of intra-abdominal pressure observed in visceral obesity is able to pump upwards the diaphragmatic muscle, compressing the parenchyma of the lung, particularly at the basal regions. Moreover, the over-stretching of the diaphragmatic muscle fibres caused by the elevation of the diaphragmatic domes produced by visceral fat can decrease the contractile efficiency of the diaphragmatic muscle [15]. The pumping effect of visceral fat on the diaphragm is enhanced by the supine position, probably causing a further reduction of pulmonary volumes and arterial oxygen tension during sleep [16]. In 13 adult patients with moderate obesity, the change of posture from the supine to upright position improves arterial oxygenation [17]. However, in patients with extreme visceral obesity, the pumping effect of visceral fat can be so pronounced that moving from the supine to the upright position does not result in an increase of pulmonary volumes and arterial oxygen tension [9].

\section{Visceral Fat and the Sleep Apnoea Syndrome}

Obesity is the most important reversible risk factor for OSAS [18]. From an epidemiological point of view, the prevalence of OSAS showed a close correlation with adiposity, rising from a prevalence of $2-4 \%$ in the general population [19] to a prevalence of at least $40 \%$ in morbidly obese patients [20]. However, the prevalence and severity of OSAS in overweight and obese patients have been shown to be more dependent on the fat distribution than on the level of total fatness. Waist circumference was a better predictor of OSAS than BMI in 1464 consecutive overweight or moderately obese men undergoing a sleep study for suspected sleep-disordered breathing [21]. By using a more precise method for the assessment of visceral fat accumulation, Vgontzas et al. [22] demonstrated that male obese patients with OSAS had a greater amount of CT-determined visceral adipose tissue into the abdomen than a group of BMI-matched men without sleep-disordered breathing. Studying 20 men with primary obesity, Shinohara et al. [23] confirmed that the prevalence of OSAS increased concomitantly with the increment of visceral adipose tissue area. All the patients with visceral adipose tissue area of more than $220 \mathrm{~cm}^{2}$ manifested OSAS, while no patients with visceral adipose tissue area of less than $120 \mathrm{~cm}^{2}$ were classified as suffering from sleep-disordered breathing (figure 2). A strong correlation between the level of visceral fat accumulation as determined by abdominal CT scan and the severity of OSAS was also demonstrated by our group in 48 morbidly obese patients of both sexes [9]. The role of abdominal visceral obesity as a predictor of OSAS in morbidly obese men has been recently questioned by Resta et al. [24] who claimed a better predictive role for the neck circumference than for the waist circumference in 57 men with $\mathrm{BMI}>30 \mathrm{~kg} / \mathrm{m}^{2}$. Neck is a potent anthropometric predictor of OSAS [25-27]. However, given the relationship between waist circumference and neck circumference levels in obese subjects [21], the relative independent role of each of these two anthropometric parameters remained to be determined.

Decreased pharyngeal patency was considered the most important pathogenetic mechanism leading to OSAS in obese patients [18]. By CT scanning, Haponik et al. [28] first demonstrated that CT scan measurements

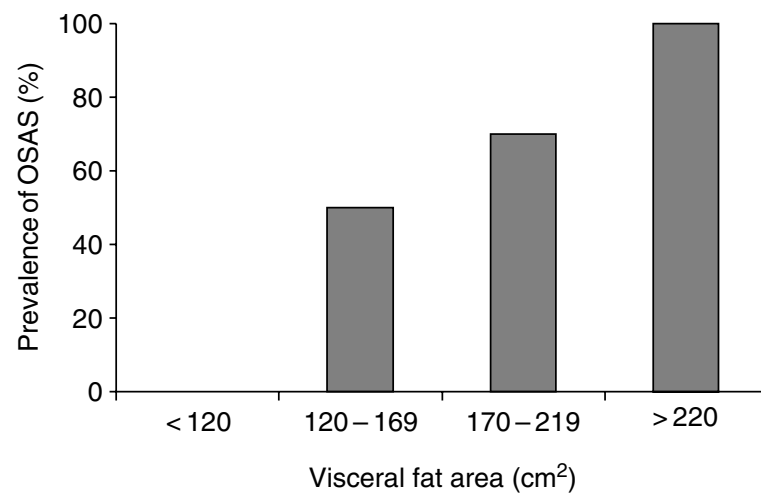

Fig. 2 Prevalence of obstructive sleep apnoea syndrome (OSAS) in relation to CT-determined intra-abdominal visceral fat area in obese subjects. OSAS was defined as an apnoea index $>5$ [23]. 
of cross-sectional areas of the nasopharynx, oropharynx and hypopharynx were significantly reduced in 20 mildly obese middle-aged men with OSAS as compared to 10 control subjects. In this small group, reduced pharyngeal size correlated with increased sleepdisordered breathing rates and more severe nocturnal oxygen desaturation [28]. A reduction of the cross-sectional area of the upper airways was also found by CT in patients with morbid obesity and OSAS [29]. We recently confirmed a reduced pharyngeal size in morbidly obese patients with OSAS by using acoustic reflection technique [30]. Acoustic analysis of the upper airways showed that the cross-sectional area was reduced along the length of the pharynx, as shown by the two paradigmatic pharyngometric curves depicted in figure 3.

Reduction in pharyngeal size in obese patients with OSAS has been attributed to a mass loading effect produced by fat deposited around the upper airways. By using nuclear magnetic resonance (NMR), Horner et al. [31] demonstrated that patients with OSAS had larger deposit of adipose tissue around the pharynx

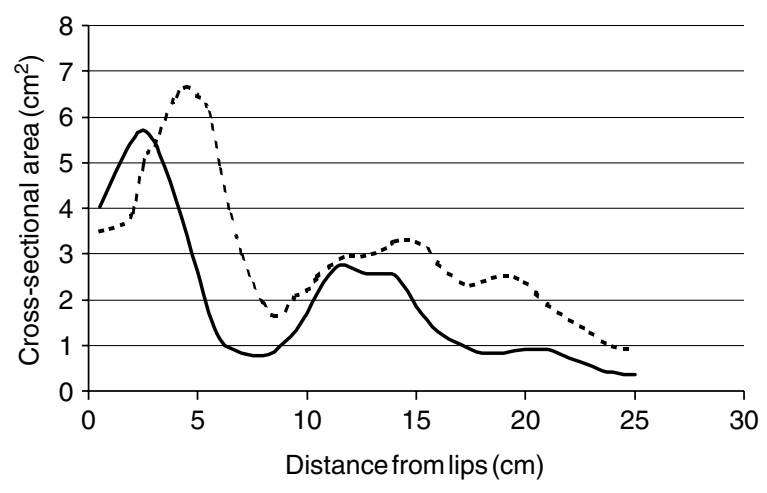

Fig. 3 Upper airways cross-sectional areas were analysed in two subjects by acoustic pharyngometry. Acoustic reflection technique uses acoustic technology to evaluate upper airways cross-sectional area from oral cavity to hypopharynx. The technique is based on the analysis of sound waves that are launched from a loudspeaker and travel along the wave tube into the subject's airways, where they are reflected. The incident waves and the reflected waves are recorded by a microphone located at the opening of the mouth. From the difference in the two signals, changes in airways area are inferred as a function of the distance from the recording microphone and a graphic plot of the variations of pharyngeal cross-sectional area $\left(\mathrm{cm}^{2}\right)$ through the length of the pharynx (cm) was obtained. The dotted line represents the pharyngometric curve of a normal weight man [body mass index (BMI) $20.8 \mathrm{~kg} / \mathrm{m}^{2}$ ] without obstructive sleep apnoea syndrome (OSAS), and the solid line represents the pharyngometric curve of a morbid obese man (BMI $82.0 \mathrm{~kg} / \mathrm{m}^{2}$ ) with severe OSAS. than control subjects. Peri-pharyngeal fat pads were close to the postero-lateral wall of the palato-pharynx, a known site of upper airways dynamic occlusion during sleep [31]. Mortimore et al. [32] demonstrated substantially increased deposits of fat laterally to the upper airway also in non-obese patients with OSAS. Finally, NMR-determined volume of adipose tissue adjacent to the airway was found to be directly related to the number of apnoeic episodes during sleeping [33].

Alternatively, a reduction in pharyngeal size has been attributed to a reduction in lung volume. Hoffstein et al. [34] demonstrated a negative correlation between lung volume and pharyngeal cross-sectional area in patients with sleep apnoea. As mentioned above, in visceral obesity the accumulation of fat inside the abdomen pumped upwards the diaphragm, causing a reduction in lung volumes [10]. The reduction of lung volume was enhanced by the supine position and during sleep [16]. Indeed, visceral CT-determined adipose tissue area was related to presence and severity of OSAS [23]. In a recent NMR study, Schäfer et al. [35] demonstrated that the amount of intra-abdominal fat, and not the size of para-pharyngeal fat, was associated with OSAS in 85 consecutive male patients.

Whatever the mechanism, it is also possible that intraabdominal fat accumulation and fat deposition around the pharynx should coexist in obese patients, being two different faces of visceral obesity. In a previous study with CT scanning, Enzi et al. [36] demonstrated a close correlation between visceral adipose tissue area of the abdomen and visceral adipose tissue area at the thoracic level in both sexes. A significant correlation between visceral adipose tissue areas and cephalometric pharyngeal dimensions has been found by Shinohara et al. [23] in obese men and women.

\section{Effects of Weight Loss}

Several experimental evidences definitely proved that the respiratory complications of obesity can be improved by body weight reduction. In the Swedish Obese Subjects (SOS) study, $87 \%$ of morbid obese patients complained at baseline with dyspnea when climbing two flights of stairs and $24 \%$ when performing simple activities of daily living such as washing or dressing. In this study, a sustained surgically induced weight loss was able to drastically reduce the incidence of exertional dyspnea, with only $19 \%$ of patients still complaining with dyspnea when climbing stairs and $3 \%$ when washing or dressing [37]. The reduction of dyspnea was associated to increased vital capacity, FRV and ERV [38,39]. Moreover, weight loss was associated with a 
clear improvement in the symptoms of OSAS [40] and a reduction in the number of the apnoeic episodes registered at polysomnography [41] in surgically treated morbidly obese patients.

One of the recent major advances in the treatment of obesity was the concept that a modest weight loss resulted in a clinically significant improvement of metabolic complications and cardiovascular risk profile [42]. It is noteworthy that also the respiratory complications of obesity appeared to be positively affected, at least in the short term, by only a moderate level of body weight reduction. Dividing 1087 morbidly obese patients according to quartiles of weight reduction, the SOS investigators were able to show that the larger reduction in the risk in continuing to suffer from dyspnea as compared to patients with stable weight $(+4.0 \mathrm{~kg})$ was obtained in patients with larger weight loss $(-41.5 \mathrm{~kg})$ [relative risk (RR) $0.02 ; 95 \%$ confidence interval (CI) 0.01-0.03]. However, a significant reduction of risk was also observed in the group of patients with only a moderate weight loss (RR 0.26 ; 95\% CI $0.18-$ 0.33). In this group, mean weight loss was $-7.9 \mathrm{~kg}$, a low level of body weight reduction in severe obesity [37]. Studying a small group of patients with OSAS and severe visceral obesity (baseline BMI of $54.7 \pm 9.5 \mathrm{~kg} / \mathrm{m}^{2}$ ) treated by intragastric balloon, we recently observed a high reduction of the number of apnoeic episodes during sleeping and a significant reduction of the daytime symptoms of OSAS with a relatively modest level of weight loss and despite the fact the patients still remained affected by severe obesity after treatment [30].

If both pulmonary function impairment and sleepdisordered breathing were more dependent on visceral fat accumulation than on the simple level of total fatness, it could be hypothesized that the improvements of respiratory complications observed with only a moderate body weight reduction could be ascribed to a selective reduction of visceral fat. In a study with total body multislices NMR, we demonstrated a preferential mobilization of abdominal visceral fat with respect of total and regional subcutaneous fat in the first phase of weight loss in a small group of six premenopausal women with visceral obesity treated by laparoscopic gastric banding [43]. It is therefore possible that the improvements of pulmonary volumes and OSAS observed after a modest weight loss should be a part of the better responsiveness of visceral than subcutaneous fat to caloric restriction. However, this hypothesis needs to be directly proved.

\section{Conclusions}

A large number of epidemiological and clinical studies suggest that visceral fat accumulation is a critical factor to determine the respiratory complications of obesity (reduced lung volumes and OSAS). A lot of evidences suggest that sleep-disordered breathing may be an independent risk factor for cardiovascular disease [44] and that it may be associated with the presence of metabolic disturbances and the insulin resistance syndrome [45-47]. Although two recent studies reported an independent association between OSAS and insulin resistance $[48,49]$, it is possible that the association between sleep-disordered breathing, cardiovascular morbidity and insulin resistance may be mediated by the deleterious mechanical and metabolic effects of visceral fat accumulation. Respiratory complications should therefore be considered as a part of the pleiotropic clinical picture of visceral obesity.

\section{References}

1 Sparrow D, Borkan GA, Gerzof SG, Wisniewski C, Silbert C. Relationship of body fat distribution to glucose tolerance. Results of computed tomography in male participants of the Normative Ageing Study. Diabetes 1986; 35: 411415.

2 Fujioka S, Matsuzawa Y, Tokunaga K, Tarui S. Contribution of intraabdominal fat accumulation to the impairment of glucose and lipid metabolism in human obesity. Metabolism 1987; 36: 54-59.

3 Seidell JC, Björntorp P, Sjöström L, Kvist H, Sannerstedt R. Visceral fat accumulation in men is positively associated with insulin, glucose, and C-peptide levels, but negatively with testosterone levels. Metabolism 1990; 9: 897-901.

4 Pouliot MC, Després JP, Nadeau A et al. Visceral obesity in men. Association with glucose tolerance, plasma insulin, and lipoporotein levels. Diabetes 1992; 41: 826-834.

5 Després JP, Nadeau A, Tremblay A, Ferland M, Lupien PJ. Role of deep abdominal fat in the association between regional adipose tissue distribution and glucose tolerance in obese women. Diabetes 1989; 38: 304-309.

6 NHLBI Obesity Education Initiative Expert Panel on the Identification, Evaluation, and Treatment of Overweight and Obesity in Adults. Clinical guidelines on the identification, evaluation, and treatment of overweight and obesity in adults. The evidence report. Obes Res 1998; 6: $515-2095$.

7 Luce JM. Respiratory complications of obesity. Chest 1980; 78: 626-630.

8 Ray CS, Sue DY, Vray G, Hansen JE, Wasserman K. Effects of obesity on respiratory function. Am Rev Resp Dis 1983; 128: 201-206.

9 Enzi G, Vianello A, Baggio MB et al. Respiratory disturbances in visceral obesity. In: Oomura Y et al. eds. Progress in Obesity Research 1990. London: John Libbey \& C, 1990; 335-339. 
10 Collins LC, Hoberty PD, Waker JF, Fletcher EC, Peiris AN. The effect of body fat distribution on the pulmonary function tests. Chest 1995; 107: 1298-1302.

11 Lazarus R, Gore CJ, Booth M, Owen N. Effects of body composition and fat distribution on ventilatory function in adults. Am J Clin Nutr 1998; 68: 35-41.

12 Harik-Khan RI, Wise RA, Fleg JL. The effect of gender on the relationship between body fat distribution and lung function. J Clin Epidemiol 2001; 54: 399-406.

13 Chen R, Tunstall-Pedoe H, Bolton-Smith C, Hannah MK, Morrison C. Association of dietary antioxidants and waist circumference with pulmonary function and airway obstruction. Am J Epidemiol 2001; 153: 157-163.

14 Sugerman HJ. Effects of increased intra-abdominal pressure in severe obesity. Surg Clin North Am 2001; 81: 1063-1075.

15 Sharp JT, Druz WS, Kondragunta VR. Diaphragmatic responses to body position changes in obese patients with obstructive sleep apnoea. Am Rev Respir Dis 1986; 133: 32-37.

16 Hudgel D, Devadatta P. Decrease in functional residual capacity during sleep in normal humans. J Appl Physiol 1984; 57: 1319-1322.

17 Hakala K, Maasilta P, Sovijärvi ARA. Upright body position and weight loss improve respiratory mechanics and daytime oxygenation in obese patients with obstructive sleep apnoea. Clin Physiol 2000; 20: 50-55.

18 Malhotra A, White DP. Obstructive sleep apnoea. Lancet 2002; 360: 237-245.

19 Young T, Peppard P, Gottlieb D. The epidemiology of obstructive sleep apnoea: a population health perspective. Am J Respir Crit Care Med 2002; 165: 1217-1239.

20 Rajala R, Partinen M, Sane T, Pelkonen R, Huikuri K, Seppalainen AM. Obstructive sleep apnoea syndrome in morbidly obese patients. J Intern Med 1991; 230: 125-129.

21 Grunstein R, Wilcox I, Yang T-S, Gould Y, Hedner J. Snoring and sleep apnoea in men: association with central obesity and hypertension. Int J Obes Relat Metab Disord 1993; 17: 533-540.

22 Vgontzas AN, Papanicolaou DA, Bixler EO et al. Sleep apnoea and daytime sleepiness and fatigue: relation to visceral obesity, insulin resistance, and hypercytokinemia. J Clin Endocrinol Metab 2000; 85: 1151-1158.

23 Shinohara E, Kihara S, Yamashita S et al. Visceral fat accumulation as an important risk factor for obstructive sleep apnoea syndrome in obese subjects. J Intern Med 1997; 241: 11-18.

24 Resta O, Foschino-Barbaro MP, Legari G et al. Sleeprelated breathing disorders, loud snoring and excessive daytime sleepiness in obese subjects. Int J Obes Relat Metab Disord 2001; 25: 669-675.

25 Davies RJO, Stradling JR. The relationship between neck circumference, radiographic pharyngeal anatomy and the obstructive sleep apnea syndrome. Eur Respir J 1990; 3: 509-514.
26 Davies RJO, Ali NJ, Stradling JR. Neck circumference and other clinical features of the obstructive sleep apnea syndrome. Thorax 1992; 47: 101-105.

27 Flemons WW, Whitelaw WA, Brant R, Remmers JE. Likelihood ratios for a sleep apnea clinical prediction rule. Am J Respir Crit Care Med 1994; 150: 1279-1285.

28 Haponik EF, Smith PL, Bohlman ME, Allen RP, Goldman SM, Bleecker ER. Computerized tomography in obstructive sleep apnea. Correlation of airway size with physiology during sleep and wakefulness. Am Rev Resp Dis 1983; 127: 221-226.

29 Suratt PM, Dee P, Atkinson RL, Armstrong P, Wilhoit SC. Fluoroscopic and computed tomographic features of the pharyngeal airway in obstructive sleep apnea. Am Rev Resp Dis 1983; 127: 487-492.

30 Busetto L, Costa G, Negrin V, Peruzza S, Enzi G. Upper airways morphometry before and after weight loss in obese patients with obstructive sleep apnea (OSAS). Int J Obes Relat Metab Disord 2003; 27: S85.

31 Horner RL, Mohiaddin RH, Lowell DG et al. Sites and sizes of fat deposits around the pharynx in obese patients with obstructive sleep apnoea and weight matched controls. Eur Resp J 1989; 2: 613-622.

32 Mortimore IL, Marshall I, Wraith PK, Sellar RJ, Douglas NJ. Neck and total body fat deposition in non obese and obese patients with sleep apnea compared with that in control subjects. Am J Respir Crit Care Med 1998; 157: 280-283.

33 Shelton KE, Woodson H, Gay S, Suratt PM. Pharyngeal fat in obstructive sleep apnoea. Am Rev Respir Dis 1993; 148: $462-466$.

34 Hoffstein V, Zamel N, Philipson EA. Lung volume dependence of pharyngeal cross-sectional area in patients with obstructive sleep apnea. Am Rev Resp Dis 1984; 130: 175-178.

35 Schäfer H, Pauleit D, Sudhop T, Gouni-Berthold I, Ewig S, Berthold HK. Body fat distribution, serum leptin, and cardiovascular risk factors in men with obstructive sleep apnea. Chest 2002; 122: 829-839.

36 Enzi G, Gasparo M, Biondetti PR, Fiore D, Semisa M, Zurlo F. Subcutaneous and visceral fat distribution according to sex, age and overweight, evaluated by computed tomography. Am J Clin Nutr 1986; 44: 739-746.

37 Karason K, Lindroos AK, Stenlöf K, Sjöström L. Relief of cardiorespiratory symptoms and increased physical activity after surgically induced weight loss. Arch Intern Med 2000; 160: 1797-1802.

38 Thomas PS, Owen ERTC, Hulands G, Milledge JS. Respiratory function in the morbidly obese before and after weight loss. Thorax 1989; 44: 383-386.

39 Weiner P, Waizman J, Weiner M, Rabner M, Magadle R, Zamir D. Influence of excessive weight loss after gastroplasty for morbid obesity on respiratory muscle performance. Thorax 1998; 53: 39-42. 
40 Dixon JB, Schachter LM, O’Brien PE. Sleep disturbance and obesity. Changes following surgically induced weight loss. Arch Intern Med 2001; 161: 10-106.

41 Harman EM, Wynne JW, Block AJ. The effect of weight loss on sleep-disordered breathing and oxygen desaturation in morbidly obese men. Chest 1982; 82: 291-294.

42 Goldstein DJ. Beneficial health effects of modest weight loss. Int J Obes Relat Metab Disord 1991; 16: 397-415.

43 Busetto L, Tregnaghi A, Bussolotto $\mathrm{M}$ et al. Visceral fat loss evaluated by total body magnetic resonance in obese women operated with laparoscopic adjustable silicone gastric banding. Int J Obes Relat Metab Disord 2000; 24: 60-69.

44 Shahar E, Whitney CW, Redline S et al. Sleep-disordered breathing and cardiovascular disease. Cross-sectional results of the Sleep Hearth Health Study. Am J Resp Crit Care Med 2001; 163: 19-25.
45 Strohl KP, Novak RD, Singer W et al. Insulin levels, blood pressure and sleep apnea. Sleep 1994; 17: 614-618.

46 Grunstein RR, Stenlof K, Hedner J, Sjöström L. Impact of obstructive sleep apnea and sleepiness on metabolic and cardiovascular risk factors in the Swedish Obese Subjects (SOS) study. Int J Obes Relat Metab Disord 1995; 19: 410-418.

47 Stoohs RA, Facchini F, Guilleminault C. Insulin resistance and sleep-disordered breathing in healthy humans. Am J Resp Crit Care Med 1996; 154: 170-174.

48 Ip MS, Lam B, Ng MM, Lam WK, Tsang KW, Lam KS. Obstructive sleep apnea is independently associated with insulin resistance. Am J Resp Crit Care Med 2002; 165: 670-676.

49 Punjabi NM, Sorkin JD, Katzel LI, Goldberg AP, Scheartz AR, Smith PL. Sleep-disordered breathing and insulin resistance in middle-aged and overweight men. Am J Resp Crit Care Med 2002; 165: 677-682. 